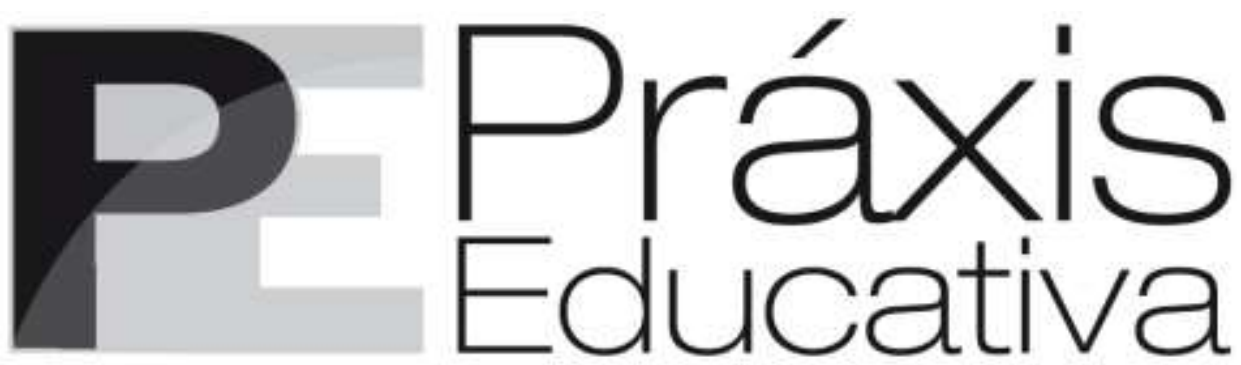

ISSN 1809-4031

eISSN 1809-4309

https://doi.org/10.5212/PraxEduc.v.17.19945.028

Seção: Artigos

\title{
Relação de forças entre as orientações da Unesco e as demandas estudantis na Lei ${ }^{\circ} 13.415 / 2017$
}

\section{Force relationship between UNESCO guidelines and student demands in Law no. 13.415/2017}

\section{Relación de fuerzas entre las directrices de la UNESCO y las demandas estudiantiles en la Ley $n^{\circ} 13.415 / 2017$}

Aldimara Catarina Brito Delabona Boutin ${ }^{*}$

iD https://orcid.org/0000-0002-0564-8290

Simone de Fátima Flach ${ }^{* *}$

http:// orcid.org/0000-0002-9445-0111

\begin{abstract}
Resumo: A partir de pesquisa mais ampla e tendo como aporte teórico o materialismo histórico e dialético, este texto tem por objetivo desvelar a relação de forças entre a Organização das Nações Unidas para a Educação, Ciência e Cultura (Unesco) e o movimento estudantil secundarista brasileiro, aqui representado pela União Brasileira dos Estudantes Secundaristas (Ubes), na materialização da Lei No 13.415/2017 Reforma do Ensino Médio. Para tanto, são analisados documentos produzidos pela Unesco, normativas, notas e demais textos produzidos pela Ubes e entrevistas semiestruturadas realizadas com seis estudantes que ocupavam cargos de diretoria da entidade no período entre 2018 e 2020. As análises são norteadas pelas categorias de hegemonia e de relação de forças extraídas do pensamento de Antonio Gramsci. Ao final, conclui-se que as orientações da Unesco e as demandas do movimento estudantil são antagônicas, visto que, de um lado, há a defesa dos interesses capitalistas; e, de outro, há a preocupação com a formação mais ampla voltada para a práxis social. Na materialização da proposta do novo Ensino Médio, houve prejuízo às demandas estudantis e supremacia de interesses burgueses defendidos pela agência internacional.

Palavras-chave: Relação de forças. Hegemonia. Unesco. Movimento estudantil. Lei No 13.415/2017.
\end{abstract}

Abstract: Based on broader research and having the historical and dialectical materialism as theoretical support, this text aims to reveal the relationship of forces between the United Nations Educational, Scientific and Cultural Organization (UNESCO) and the Brazilian Union of Secondary Students (UBES),

\footnotetext{
* Doutora em Educação pela Universidade Estadual de Ponta Grossa (UEPG).E-mail: <audiboutin@hotmail.com>.

** Doutora em Educação pela Universidade Federal de São Carlos (UFSCar). Docente da Universidade Estadual de Ponta Grossa (UEPG). E-mail: <eflach@uol.com.br>.
}

Práxis Educativa, Ponta Grossa, v. 17, e2219945, p. 1-19, 2022 Disponível em: < https:// revistas2.uepg.br/index.php/praxiseducativa $>$ 
In the materialization of Law no. 13.415/2017 - High School Reform. For that, documents produced by UNESCO, regulations, notes and other texts produced by UBES are analyzed, and semi-structured interviews carried out with six students who held positions of director of the entity in the period between 2018 and 2020. The analyzes are guided by the categories of hegemony and relationship of forces extracted from Antonio Gramsci's thinking. In the end, it is concluded that the guidelines of UNESCO and the demands of the student movement are antagonistic, because, in one hand, there is the defense of capitalist interests, and, on the other hand, there is a concern with a broader formation focused on social praxis. In the materialization of the proposal for the new High School, there was loss to the student demands and the supremacy of bourgeois interests defended by the international agency.

Keywords: Relationship of forces. Hegemony. UNESCO. Student movement. Law no. 13.415/2017.

Resumen: A partir de investigación más amplia y teniendo como aporte teórico el materialismo histórico y dialéctico, este texto tiene el objetivo de revelar la relación de fuerzas entre la Organización de las Naciones Unidas para la Educación, Ciencia y Cultura - UNESCO y el movimiento estudiantil secundarista brasileño, aquí representado por la Unión Brasileña de Estudiantes Secundaristas - UBES, en la materialización de la Ley $N^{\circ}$ 13.415/2017 - Reforma de la Educación Secundaria. Para ello, son analizados documentos producidos por la UNESCO, normativas, notas y otros textos producidos por la UBES, y entrevistas semiestructuradas realizadas a seis estudiantes que ocupaban cargos de dirección de la entidad en el período comprendido entre 2018 y 2020. Los análisis son guiados por las categorías de hegemonía y de relación de fuerzas extraídas del pensamiento de Antonio Gramsci. Al final, se concluye que las orientaciones de la UNESCO y las demandas del movimiento estudiantil son antagónicas, ya que, por un lado, está la defensa de los intereses capitalistas y por otro, está la preocupación por una formación más amplia enfocada en la praxis social. En la materialización de la propuesta de la nueva Educación Secundaria hubo una pérdida de las demandas estudiantiles y la supremacía de los intereses burgueses defendidos por el organismo internacional.

Palabras clave: Relación de Fuerzas. Hegemonía. UNESCO. Movimiento Estudiantil. Ley $\mathrm{N}^{\circ}$ $13.415 / 2017$.

\section{Introdução}

As ocupações estudantis de 2016 reafirmaram que a educação efetivamente pública e de qualidade é uma das demandas que orientam a organização política dos jovens brasileiros. Iniciadas no estado do Paraná, essas ocupações estiveram presentes em 1.197 instituições públicas de ensino, conforme a União Brasileira dos Estudantes Secundaristas - Ubes (2016), em um movimento que teve, dentre outros motivos, de opor-se à Medida Provisória (MP) $\mathrm{N}^{\circ}$ 746, de 22 de setembro de 2016, que visava reformular o Ensino Médio no Brasil (BRASIL, 2016a).

Mesmo sob protestos e manifestações de parte significativa da sociedade e, também, tendo sido um dos motivos das ocupações escolares, a Lei $\mathrm{N}^{\circ} 13.415$ foi promulgada no dia 16 de fevereiro de 2017 e trouxe, em seu bojo, a fragmentação do currículo. Essa fragmentação ocorre por meio da formação comum e do engodo previsto pela oferta dos itinerários formativos: "I - linguagens e suas tecnologias; II - matemática e suas tecnologias; III - ciências da natureza e suas tecnologias; IV - ciências humanas e sociais aplicadas; V - formação técnica e profissional." (BRASIL, 2017, p. 1). Além disso, há previsão de atuação de profissionais com "notório saber", em detrimento à contratação de profissionais habilitados, a diluição de disciplinas em estudos e práticas, a realização de parcerias entre entidades públicas de ensino e o setor privado, em séria afronta às responsabilidades do poder público com a oferta educacional e, ainda, o fomento ao ensino em tempo integral, sem a consideração das peculiaridades da realidade em que os estudantes vivem.

Esses elementos dialogam com uma proposta de Ensino Médio voltada ao mercado, no qual o capital determina "[...] as alterações no sistema educacional e a burguesia capitalista, como

Práxis Educativa, Ponta Grossa, v. 17, e2219945, p. 1-19, 2022 Disponível em: <https:// revistas2.uepg.br/index.php/praxiseducativa $>$ 
personificação do capital, segue cumprindo seu papel de adequar permanente a educação, por meio da política educacional, as necessidades do capital" (LOPES; MOREIRA, 2021, p. 102).

De acordo com Ferreira (2017, p. 304), a “[...] contrarreforma do ensino médio é parte integrante de uma agenda globalmente estruturada da educação", que é oposta à formação humana para a práxis social, a qual subsidia o desenvolvimento do pensamento crítico, a compreensão do mundo e da realidade. Assim, "[...] uma reforma do ensino médio precisa enfraquecer a relação determinante entre a origem social dos jovens e seu percurso escolar", exigindo "[...] o compartilhamento de estudos científicos capazes de construir um diagnóstico mais fiel da realidade, além de esforços políticos colaborativos entre os entes federativos" (FERREIRA, 2017, p. 304). Assim, tomando como parâmetro a Lei No 13.415/2017, Ferreira (2017, p. 304) explicita que, mais do que mudar o currículo do Ensino Médio, é importante "[...] relacionar o conhecimento da complexa e diversificada realidade dos jovens e integrar o trabalho dos professores em atividades pedagógicas coletivas e interessadas no aprofundamento da complexidade do conhecimento científico e cultural".

O Ensino Médio é objeto de disputas políticas, por meio das quais se revelam os interesses de determinada classe ou grupo social. As ocupações secundaristas colocaram em evidência a relação de forças que existem em torno do Ensino Médio brasileiro. De um lado, o movimento estudantil, que, historicamente, tem se organizado em torno de demandas que dialogam com uma educação efetivamente pública e de qualidade. De outro, o capital que impõe um Estado mínimo alinhado às orientações políticas dos organismos internacionais, contribuindo para a realização de reformas educacionais impositivas, implementadas sem debate aprofundado com a sociedade civil.

Desses organismos internacionais, destacamos a Organização das Nações Unidas para a Educação, Ciência e Cultura (Unesco), cuja interferência na área da educação brasileira se intensificou no ano de 1992 com a Declaração Mundial sobre Educação para Todos, elaborada em 1990 durante a Conferência Mundial de Educação para Todos, realizada na cidade de Jomtien, na Tailândia. Naquela ocasião, a agência firmou acordo de cooperação técnica com o Ministério da Educação brasileiro, para a realização de projetos, comprometidos com cinco áreas temáticas: educação, ciências naturais, ciências sociais, cultura, comunicação e informação. O referido acordo visava reunir "[...] verbas nacionais e competência internacional”" (UNESCO, 2006, p. 7).

A partir de Gramsci (2016, p. 83), é possível compreendermos a Unesco como um "centro de irradiação" e "difusão" de ideais atrelados à padronização do mesmo modo de ser, agir e pensar das classes subalternas, portanto da sociedade civil com influência internacional, a qual, fundamentada no compromisso de universalização da cultura, ganha adesão em políticas, programas ou iniciativas que legitimam um projeto societário hegemônico. Dessa forma, a agência contribui para a manutenção da atual estrutura societária, pois o "econômico corporativo" (GRAMSCI, 2016, p. 41) ganha primazia em relação ao "ético político" (GRAMSCI, 2016, p. 41), orientando os modos de pensar das classes subjugadas.

Com base nessas questões iniciais, sendo derivado de uma pesquisa mais ampla ${ }^{1}$ (BOUTIN, 2020), a partir do referencial materialista histórico e dialético, o presente texto tem por objetivo desvelar a relação de forças entre a Unesco e o movimento estudantil secundarista brasileiro, aqui representado pela Ubes, na materialização da Lei № 13.415/2017 - Reforma do Ensino Médio. Para tanto, a partir da análise de documentos produzidos pela Unesco e pela Ubes e seis entrevistas semiestruturadas, realizadas com os diretores da entidade estudantil, buscamos identificar as

\footnotetext{
${ }^{1}$ Pesquisa realizada com o apoio da Fundação Araucária (FA)/Coordenação de Aperfeiçoamento de Pessoal de Nível Superior - Brasil (CAPES) - Código de Financiamento 001.
}

Práxis Educativa, Ponta Grossa, v. 17, e2219945, p. 1-19, 2022 Disponível em: <https:// revistas2.uepg.br/index.php/praxiseducativa $>$ 
orientações da agência internacional e as demandas dos jovens brasileiros e, com isso, avaliar a sua presença no novo Ensino Médio.

Os documentos da Ubes foram selecionados por meio de uma busca na página digital da entidade, sendo utilizados os seguintes descritores: Ensino Médio, Novo Ensino Médio, Medida Provisória $\mathrm{N}^{\circ}$ 746, Lei $\mathrm{N}^{\circ} 13.415$ e Reforma do Ensino Médio. A partir dessa triagem, foram localizadas notas de repúdio, manuais informativos, atas oriundas de eventos (fóruns e congressos estudantis), entre outras publicações. Desses documentos, foram selecionados aqueles que mencionavam o posicionamento dos estudantes sobre a reforma do Ensino Médio ou que explicitavam as demandas dos estudantes em relação a essa etapa da Educação Básica. Ao final, três documentos, publicados entre os anos de 2016 e 2018, mostraram-se importantes para a análise: 1) Nota de repúdio à MP do Ensino Médio; 2) Ata da eleição dos delegados: $42^{\circ}$ Congresso da Ubes (Conubes); e 3) Construindo nossa escola.

As entrevistas foram realizadas com os seis membros da diretoria da Ubes (gestão 20182020), via mídias digitais (Skype e Hungouts), as quais duraram, em média, 50 minutos, sendo gravadas e transcritas para posterior análise. As questões de pesquisa eram abertas e buscavam identificar as demandas da Ubes para o Ensino Médio, como a reforma impacta na qualidade e na democratização do Ensino Médio brasileiro e qual é a proposta de Ensino Médio defendida pela Ubes.

Em relação aos procedimentos éticos da pesquisa, convém ressaltarmos que tanto o Projeto de Investigação quanto os documentos pertinentes foram submetidos e aprovados pelo sistema do Comitê de Ética em Pesquisa (CEP)/Comissão Nacional de Ética em Pesquisa (Conep). A submissão de tais documentos ao referido órgão é uma iniciativa importante, pois, conforme justificam Mainardes e Cury (2019, p. 27), “[...] todas as pesquisas que envolvam seres humanos devem ter como princípio fundante a dignidade da pessoa humana", o que implica o "[...] respeito aos participantes, consentimento, avaliação cuidadosa de potenciais riscos aos participantes, compromisso com o benefício individual, social e coletivo das pesquisas [...]". Nesse sentido, a pesquisa foi norteada pelo “[...] respeito aos direitos humanos e à autonomia da vontade [...]", além de apurado compromisso com os "[...] padrões elevados de pesquisa, integridade, honestidade, transparência e verdade [...]", "[...] defesa dos valores democráticos, da justiça e da equidade [...]" e a "[...] responsabilidade social" (MAINARDES; CURY, 2019, p. 27). Assim, na perspectiva ética adotada, a pesquisa foi conduzida por princípios e procedimentos éticos desde a tessitura do projeto de pesquisa, até a interpretação, análise e publicização dos resultados.

A seleção dos documentos da Unesco ocorreu por meio de um levantamento na página digital da agência. Foram localizados 20 documentos sobre educação ou políticas educacionais para a juventude, publicados entre os anos de 2001 e 2017. Destes, seis documentos foram selecionados em razão de que tratavam em específico sobre o Ensino Médio: 1) O Ensino Médio no século XXI: desafios tendências e prioridades; 2) Políticas públicas de, com e para juventudes; 3) Reforma de educação secundária: rumo à convergência entre a aquisição de conhecimento e o desenvolvimento de habilidade; 4) Ensino Médio e Educação Profissional: desafios da integração; 5) Protótipos curriculares de Ensino Médio e Ensino Médio integrado: resumo executivo; 6) Currículo integrado e Ensino Médio: das normas à prática transformadora.

Para atingirmos o objetivo perseguido, este artigo expõe as categorias gramscianas de hegemonia e relação de forças, apresenta análise dos documentos selecionados e das entrevistas realizadas de forma a identificar as demandas do movimento estudantil e orientações da Unesco para o Ensino Médio, a possível relação de forças entre ambos e como ela se expressa na Lei $\mathrm{N}^{\circ}$ 13.415/2017. Por fim, há a indicação de que no novo Ensino Médio, por meio dos aparelhos privados de hegemonia da classe dominante, houve a primazia do "econômico corporativo"

Práxis Educativa, Ponta Grossa, v. 17, e2219945, p. 1-19, 2022 Disponível em: <https:// revistas2.uepg.br/index.php/praxiseducativa $>$ 
(GRAMSCI, 2016, p. 41) e, assim, as orientações da Unesco foram materializadas no texto da lei, em detrimento das demandas do movimento estudantil.

\section{Discussões sobre as categorias hegemonia e relação de forças}

A compreensão sobre as categorias hegemonia e relação de forças faz-se necessária para uma visão mais ampla acerca dos interesses e dos compromissos que se fazem presentes em propostas políticas e se materializam em documentos governamentais e legais. No campo da educação, essas categorias ajudam a compreender os caminhos traçados para o conjunto dos homens que compõem determinada classe.

Os "organismos privados de hegemonia" (GRAMSCI, 2016, p. 121), representados por instituições educacionais, políticas e culturais, entre outras, cooperam para que as visões de mundo da classe hegemônica se tornem historicamente verdadeiras e sejam arraigadas como ideias comuns de toda a sociedade. Nessa perspectiva, as lutas que emergem do antagonismo entre as classes são ofuscadas e menosprezadas. Como dimensão ampliada, composto por sociedade civil + sociedade política, o Estado exerce a função de "ordenador da ideologia" (GRAMSCI, 2014, p. 375) e funciona como o cimento que molda e une toda sociedade em torno da visão de mundo expressa pela hegemonia de determinada classe.

Ao ampliar-se no âmbito da sociedade civil, o Estado "educa" o "consenso" por meio dos "[...] organismos privados, deixados à iniciativa privada da classe dirigente" (GRAMSCI, 2016, p. 121). Assim, no entrelaçamento entre sociedade civil e sociedade política, ocorre a subordinação dos subalternos frente à "concepção de mundo" dominante, de modo que estes não percebam a relação de submissão e exploração à qual estão expostos.

Essa relação de hegemonia não ocorre descolada do processo dialético, pois, conforme Semeraro (1999, p. 76), na sociedade civil, "[...] se confrontam diversos projetos de sociedade, até prevalecer um que estabeleça a direção geral na economia, na política e na cultura". Assim, ganham materialidade na luta política os embates entre subalternos e dominantes, entre possibilidades de reforma ou revolução e entre as concepções de mundo conservadoras e aquelas que visam à emancipação humana.

A leitura de Gramsci $(2001,2016)$ indica que a hegemonia subalterna se apoia em uma reforma intelectual e moral, capaz de instrumentalizar a interpretação "realista e historicista" da "realidade efetiva" (GRAMSCI, 2016, p. 35). A partir disso, a compreensão das "forças que atuam na história de um determinado período" precisa ser entendida na articulação entre estrutura e superestrutura. Nesse sentido, as relações de força articulam-se a três momentos. Caracterizado como relação de forças sociais, no primeiro momento, "[...] com base no grau de desenvolvimento das forças materiais de produção", as relações de força se ligam "[...] à estrutura objetiva independente da vontade dos homens" (GRAMSCI, 2016, p. 40).

O segundo momento, caracterizado como "relações de forças políticas" em razão da "[...] homogeneidade de autoconsciência e de organização, alcançado pelos vários grupos sociais" (GRAMSCI, 2016, p. 40 - 41), organiza-se em diferentes graus, conforme "momentos de consciência política coletiva" (GRAMSCI, 2016, p. 41), a saber:

a) Econômico corporativo: ocorre quando não há consciência de classe, pois a solidariedade existe, mas recai sobre o corporativismo e os interesses de um determinado grupo (GRAMSCI, 2016). 
b) Consciência da solidariedade: ocorre quando a solidariedade permanece "no campo meramente econômico" (GRAMSCI, 2016, p. 41), pois ainda não houve a superação do "econômico corporativo". Nesse momento, o Estado é um instrumento que regula "o direito de participar da legislação e da administração" (GRAMSCI, 2016, p. 41).

c) Fase estritamente política: ocorre quando há "unicidade dos fins econômicos e políticos", "unidade intelectual e moral" e os "interesses corporativos" de um grupo são superados para ceder lugar ao coletivo (GRAMSCI, 2016, p. 41). Nessa fase, há a "[...] passagem nítida da estrutura para a esfera das superestruturas complexas" (GRAMSCI, 2016, p. 41), e as ações do Estado são voltadas para a criação de condições para a hegemonia de um grupo.

Por fim, Gramsci (2016, p. 43) afirma que na "relação das forças militares" há diferenças entre o "[...] militar em sentido estrito, ou técnico militar, e o grau que pode ser chamado de político militar". Assim, a "[...] relação de opressão militar de um Estado sobre uma nação que procura alcançar sua independência estatal" (GRAMSCI, 2016, p. 43) não consiste em uma relação "puramente militar, mas político-militar", ainda que as forças sejam "puramente militares", suas ações atendem aos interesses dominantes.

A categoria "relações de força" indica-nos, portanto, que a realidade é permeada por contradições econômicas, políticas e sociais e que nela as forças se confrontam dialeticamente em um movimento de conservação e de superação. Nessa disputa, situam-se pessoas, grupos ou instituições, que, no âmbito da sociedade civil, desenvolvem ações que representam interesses das classes dominantes e dominadas.

O movimento estudantil e a Unesco são entidades da sociedade civil que compõem as forças políticas em determinado momento histórico e se organizam em torno de demandas e de orientações para a educação. Os projetos de mundo dessas entidades não estão isentos de ideologias influenciadas pela conjuntura econômica, social e política e objetivam produzir impactos na "realidade efetiva" (GRAMSCI, 2016, p. 35) no sentido de conservá-la ou transformá-la. Diante disso, é importante questionarmos se, na reforma do Ensino Médio - Lei No 13.415/2017 - foram contempladas, mesmo que minimamente, as demandas do movimento estudantil, ou se essa reforma se alinha às orientações da Unesco para a educação secundarista. Na sequência, a partir do material empírico, apresentamos as demandas do movimento estudantil e as orientações da Unesco para o Ensino Médio.

\section{Demandas do movimento estudantil para o Ensino Médio}

A Ubes é a organização representativa dos estudantes de Ensino Médio e Técnico no Brasil. Tendo sido fundada no dia 25 de julho de 1948, a entidade organiza-se nas seguintes instâncias deliberativas:

[...] o Encontro de Grêmios, que reúne os grêmios estudantis do Brasil; o Conselho Nacional de Entidades Gerais (Coneg), que agrega as entidades municipais e estaduais secundaristas; e o Congresso Nacional da UBES (Conubes), formado por todas as entidades e também por todos os estudantes que quiserem, de maneira livre, participar. (UBES, 2022, n.p.)

Além dessas instâncias, a entidade organiza eventos temáticos com destaque para o Encontro de Mulheres Estudantes e o Encontro Nacional de Escolas Técnicas, nos quais são pautados debates sobre a conjuntura social, política e econômica do país. Situada nesses debates, a educação é uma pauta que mobiliza as iniciativas dos secundaristas no interior da Ubes, 
principalmente na oposição aos projetos neoliberais que integram as políticas educacionais da atualidade, privatizações e sucateamento das entidades públicas de ensino (UBES, 2022).

No que se refere ao posicionamento da Ubes, em relação à MP $\mathrm{N}^{\circ} 746 / 2016$, conferimos destaque ao documento "Nota de repúdio à MP 746" (UBES, 2016), publicado no dia do lançamento da proposta de reformulação do Ensino Médio brasileiro ${ }^{2}$. Nesse documento, os estudantes posicionaram-se contra as mudanças no Ensino Médio e apresentaram alguns posicionamentos em defesa de uma educação emancipadora, socialmente referenciada:

Queremos uma escola que de fato contribua para a emancipação dos estudantes, que não seja tecnicista e nos compreenda como agentes transformadores da sociedade. Não queremos mais decorar a tabela periódica e a fórmula de bhaskara e, sim, compreendêlas no nosso tempo e cotidiano. A gente quer de verdade é uma escola integralizada em tempo integral e não apenas mais horas do mesmo ensino que está aí. [...]. Queremos mais verdades sobre as atrocidades da ditadura militar de 1964 dentro das escolas para que todo jovem saiba o valor da democracia e do que um golpe e golpistas são capazes quando tomam à força o poder. Acima de tudo, nós, estudantes secundaristas brasileiros, queremos participar e opinar sobre essa nova escola e a reforma do ensino médio. Queremos que as escolas públicas possam ser democráticas, laicas e de qualidade social. Por isso, repudiamos a MP apresentada sem diálogo e sem participação da sociedade. (UBES, 2016, n.p.).

A educação requerida pelo movimento estudantil secundarista é consubstanciada em saberes que ampliam os horizontes dos jovens e possibilitam um processo emancipatório, não apenas político, mas humano. Tais saberes dizem respeito aos conhecimentos históricos, científicos e artísticos, os quais, se articulados com a realidade dos jovens, instrumentalizam o pensamento crítico e ampliam as possibilidades da participação democrática nas decisões tomadas na escola e na sociedade. A escola na qual se realizaria essa educação seria uma escola efetivamente pública e de qualidade universalizada.

As perspectivas para o Ensino Médio brasileiro também foram debatidas no Congresso Nacional da Ubes - $42^{\circ}$ Conubes de 2017. No documento "Resolução de educação aprovada no $42^{\circ}$ Conubes" (UBES, 2017), a Ubes explicita os limites da reforma do Ensino Médio:

A Reforma aprovada passou por cima de todos os acúmulos de décadas do movimento educacional e estudantil. [...]. Ou seja, é uma contraofensiva à nossa luta por um Ensino médio emancipador. A reforma destruiu os conteúdos transformando tudo nos chamados itinerários formativos, uma fusão de matérias visando rebaixar sua qualidade. Estabeleceu uma orientação formativa tecnicista minimizante, profissionalizante e voltada para as demandas do mercado, excluindo da grade obrigatória disciplinas críticas como História e Geografia. Desapareceu, também, o Espanhol como língua opcional, dificultando a integração brasileira com os vizinhos da América Latina. As disciplinas de Artes, Sociologia, Filosofia e Educação Física, passam a ser "estudos e práticas" obrigatórias, não sendo especificado como isso se dará. Passou a valer a figura do professor de "notório saber", desvalorizando ainda mais a formação através das licenciaturas e incentivando a contratação de profissionais não qualificados. (UBES, 2017, p. 1, grifo nosso).

Além de realizar oposição à reforma do Ensino Médio e ao seu caráter autoritário, a Ubes posiciona-se contra as políticas implementadas pelo Governo Temer e dá-nos pistas do que seria uma educação emancipadora:

A escola de nossos sonhos é verdadeiramente democrática e popular: os grêmios têm autonomia de atuação; o conhecimento produzido é voltado às demandas da classe trabalhadora brasileira e seus filhos, apontando para um desenvolvimento social

${ }^{2}$ A reforma do Ensino Médio foi lançada via MP No 746 no dia 22 de setembro de 2016.

Práxis Educativa, Ponta Grossa, v. 17, e2219945, p. 1-19, 2022

Disponível em: <https:// revistas2.uepg.br/index.php/praxiseducativa $>$ 
sustentável e para a soberania nacional científica e tecnológica; os estudantes possuem autonomia diante do seu processo de aprendizagem, agindo enquanto sujeitos ativos; as instituições são acessíveis a pessoas com todos os tipos de necessidades específicas e, também, à comunidade; os grandes debates são feitos em Congressos Escolares com participação de estudantes, professores, técnicos e responsáveis e os diretores são escolhidos através de eleições diretas. Mas, esta escola não cabe no capitalismo, por isso, temos o dever de lutar também pela transformação radical da sociedade. (UBES, 2017, p. 2-3, grifo nosso).

Nessa perspectiva, uma educação emancipadora é articulada com a superação radical do modo de produção capitalista. Assim, os estudantes consideram a necessidade de construir uma escola que estimule o debate, a participação democrática e a autonomia de alunos e de professores e reforçam a demanda pelo acesso aos conhecimentos sistematizados pela humanidade, a melhoria das estruturas das escolas, a concessão de bolsas de iniciação científica, de modo a enriquecer as experiências em pesquisas e incentivar a permanência dos jovens no Ensino Médio e a valorização dos docentes das escolas públicas:

É preciso ainda intensificar a produção de conhecimento na escola. Não é suficiente que as escolas tenham apenas acesso à internet e equipamentos tecnológicos, precisamos que seja investido no ensino técnico para além dos IFs [Institutos Federais] e que seja concedida bolsas de iniciação científica como já acontece no ensino superior. Além disso, é urgente que o movimento secundarista se coloque ao lado dos professores de nosso país na defesa de um salário justo, com melhores condições de trabalho, assim como em suas lutas contra a indefensável reforma trabalhista e a deforma da previdência em curso. (UBES, 2017, p. 3).

O "Ensino Médio emancipador" situa-se para além do Ensino Médio da atualidade, pois seria organizado de modo a contemplar os interesses e as necessidades dos alunos vinculados à classe trabalhadora. Essa perspectiva também se faz presente no manual "Construindo nossa escola" (UBES, 2018), com o objetivo de servir de referencial para os participantes do Seminário Nacional de Educação, evento em que cerca de 300 estudantes secundaristas do Brasil tiveram a oportunidade de debater a educação pública. Nesse documento, a Ubes situa os estudantes no debate sobre as atuais políticas educacionais e apresenta um posicionamento crítico em relação à educação na atual conjuntura, destacando que a educação e um ensino democrático, de qualidade e efetivamente público são prioridades para o movimento estudantil secundarista.

No que se refere em específico à MP N $\mathrm{N}^{\circ}$ 746/2016, o "Construindo nossa escola" argumenta que essa MP "[...] tenta criar uma falsa expectativa de oportunidades e opções” (UBES, 2018, p. 24), destacando ainda que a proposição de "uma escola com maior custo" entra em contradição com os ajustes fiscais e cortes na educação viabilizados pela Proposta de Emenda à Constituição (PEC) N 55, de 2016 (BRASIL, 2016b).

As entrevistas realizadas com os diretores da Ubes também expressam as demandas do movimento estudantil para a educação e um posicionamento crítico à reforma do Ensino Médio. De acordo com o Diretor (B), essa reforma é voltada "para apertar parafusos" e não para formar "pensadores e cientistas", capacita os jovens apenas para trabalhos simples e lhes tira a possibilidade de uma ampla formação.

Tendo como referência a análise das falas dos entrevistados, as seguintes demandas da Ubes para o Ensino Médio são sistematizadas a seguir:

a) Valorização dos profissionais da educação; investimentos efetivos nas escolas públicas; participação democrática: 
Nós precisamos cumprir as metas do Plano Nacional de Educação, dentre elas a principal meta que é o financiamento da educação. A gente precisa chegar aos 10\% do PIB na educação pública, porque hoje a gente não tem que pegar o dinheiro público e dar pro Sistema S, pro SENAI, pro SENAC. Tem que se investir na escola pública, em uma escola em que o estudante participe das decisões, não só do currículo escolar, mas opinar sobre qual é a escola que a gente quer. (Diretor A, 2018, grifos nossos).

b) Acesso ao conjunto de conhecimentos produzidos pela humanidade; formação do pensamento crítico; possibilidade de acesso ao Ensino Superior; investimentos nas escolas públicas; ensino integral, noturno, plural e democrático:

[...] nós precisamos de uma escola, que tenha um número de matérias suficientes para o aluno formar seu senso crítico. Para você conseguir escolher entre várias profissões, pensar o que você quer fazer do seu futuro, uma escola que tenha cadeira, que tenha merenda, o básico do básico [...]. A gente não acha ruim o ensino integral, mas a gente precisa do ensino integral e do ensino noturno. Precisa ajudar a galera que precisa trabalhar em um turno e estudar em outro, que não é o que está acontecendo nas escolas agora. Então, acho que uma escola mais plural, mais democrática, onde todos possam escolher o seu diretor, com grêmio estudantil para que os estudantes possam se organizar com mais cultura, tendo consciência que o conhecimento não se dá só na sala de aula passado pelo professor de português ou de matemática e acho que isso é o básico do básico que é o primeiro passo para uma nova escola e para um novo Brasil também. (Diretor B, 2018, grifos nossos).

A reforma do Ensino Médio vem junto num momento em que a própria Emenda Constitucional 95 barra os investimentos em saúde e educação, então como é que se vai fazer uma reformulação no Ensino Médio se o Ensino Médio não tem um investimento adequado? A gente queria que fosse seguido o Plano Nacional de Educação para gente com 10\% do PIB para a educação e não dessa forma como essa reforma que está sendo colocada agora. (Diretor D, 2018, grifos nossos).

c) Gratuidade e qualidade da educação e do Ensino Médio; ampliação dos investimentos nas escolas públicas:

A proposta de Ensino Médio defendida pela Ubes é a de um Ensino Médio e educação totalmente gratuitos, públicos e de qualidade. [...]. Não é gratuita se a gente tiver que pagar pra ir pra escola, [...] se tiver aula de artes, por exemplo, e tu precisar que levar material [...]. O [ocultada a identidade e cargo que o aluno ocupa na Ubes], diz que nós precisamos de uma escola de Ensino Médio que seja do tamanho dos nossos sonhos, e eu acho que é bem isso, nós queremos e defendemos uma escola sem preconceito, uma escola que tenha estrutura real pra funcionar, pra acontecer. Uma escola com a cara do jovem. [...]. Se é público, precisa ser pra todos. (Diretor F, 2018, grifos nossos).

d) Inclusão digital; acesso ao conjunto dos conhecimentos produzidos pela humanidade; investimentos nas escolas; ensino plural e democrático; possibilidade de acesso ao Ensino Superior.

[...] que possa ter o ensino da filosofia, da sociologia, das artes e educação física, como matérias prioritárias também e obrigatórias, fazendo a inclusão digital não seja toda ela no ensino a distância, mas que seja necessária a implementação, até porque tem muita gente que mora em pontos afastados da cidade e que não tem acesso à internet. Então nós costumamos dizer que nós temos mais tecnologia na palma de nossa mão do que na sala de aula. [...]. Então nós queremos uma educação que seja includente, mas enfim que possa ter a participação da comunidade escolar, mas que tenha a participação também da sociedade [...], até porque existe uma coisa chamada Conselho de Classe, Conselho de turma, Conselho da escola que é formado por pais, professores, alunos, gestores. Enfim, [...] nós queremos uma educação que toque nesses pontos, que cada vez pense não só no empresariado, na mão de obra, mas que pense o estudante pra que, quando acabar o Ensino Médio, ele não queira só procurar emprego, mas que queira ingressar no Ensino Superior. Nós queremos [...] que seja um ensino que aglomere mais pessoas dentro das universidades e das escolas [...]. (Diretor C, 2018, grifos nossos).

Práxis Educativa, Ponta Grossa, v. 17, e2219945, p. 1-19, 2022 
e) Ampliação o acesso ao mercado de trabalho e Ensino Superior; aulas práticas, investimentos nas escolas públicas; ensino integral e técnico de qualidade; políticas que conciliem o binômio trabalho e estudo.

[...] a gente precisa de um Ensino Médio que seja atrativo, a gente precisa fazer com que o estudante saia do Ensino Médio e que ingresse na universidade, no mercado de trabalho. Então, a gente defende que no ensino nédio possa ter estágio, [...] aula prática e [...] laboratórios funcionando nas escolas. [...]. De forma geral, a gente sabe que precisa de um ensino integral, de um ensino profissional e técnico de qualidade, a gente precisa de estágio de laboratório [...]. A gente defende o Ensino Médio com assistência estudantil pra que o estudante tenha as condições de permanecer no Ensino Médio, pra que não tenha que optar entre estudar ou trabalhar [...]. (Diretor E, 2018, grifos nossos).

As demandas do movimento estudantil para o Ensino Médio partem de uma análise da realidade, de modo a contemplar as necessidades dos jovens cuja origem social se vincula à classe trabalhadora. Tais demandas priorizam a universalização e o acesso ao conhecimento, o estímulo ao pensamento crítico e uma educação que desenvolva as potencialidades humanas e não apenas vise o mercado de trabalho. É possível inferir que a educação defendida pelos estudantes é democrática, visto que objetiva incluir os jovens, a comunidade e os professores no debate social, político e econômico; estimula a participação, a pesquisa e a criatividade; e, consequentemente, se caracteriza como uma educação igualitária voltada à efetiva liberdade.

$\mathrm{Na}$ sequência, analisamos os documentos da Unesco, em busca de identificarmos as orientações da agência para o Ensino Médio.

\section{Orientações da Unesco para o Ensino Médio}

A Unesco foi fundada no dia 16 de novembro de 1945, após a II Guerra Mundial, com o objetivo de "[...] fazer avançar através das relações educacionais, científicas e culturais entre os povos do mundo, os objetivos da paz internacional, e do bem-estar comum da humanidade [...]" (UNESCO, 2002, p. 2). No que se refere em específico à área da Educação, o objetivo da Unesco é "[...] auxiliar os países membros a atingir as metas de Educação para Todos, promovendo o acesso e a qualidade da educação em todos os níveis e modalidades, incluindo a educação de jovens e adultos" (BRASIL, 2018, n.p.). Tendo isso em vista, a agência desenvolve um conjunto de iniciativas que visam fortalecer as "[...] capacidades nacionais, além de prover acompanhamento técnico e apoio à implementação de políticas nacionais de educação, tendo sempre como foco a relevância da educação como valor estratégico para o desenvolvimento social e econômico dos países" (BRASIL, 2018, n.p.).

Para conhecer as orientações da Unesco para o Ensino Médio, inicialmente analisamos o relatório Ensino Médio no século XXI: desafios tendências e prioridades, no qual a agência enfatiza a necessidade da redefinir os "objetivos" e as "funções" da educação secundarista para o século XXI (UNESCO, 2003, p. 7). Tendo isso em vista, a Unesco (2003, p. 23) defende um Ensino Médio pautado em "novos modos de trabalhar", "flexíveis e facilitadores" das aprendizagens, os quais requerem "especialistas num tema e/ou educadores gerais" (UNESCO, 2003, p. 25) , ou seja, “[...] equipes educativas abertas a outras categorias além da de professores [...]" e "[...] novas, democráticas e descentralizadas modalidades de administrar as suas escolas" (UNESCO, 2003, p. 25).

Nesse documento, a Unesco (2003) ressalta a necessidade de promover o acesso equilibrado entre a educação de massa e a seletiva. Esse acesso seria viabilizado por "[...] um esquema de parceria entre os governos e outros provedores (privados, organizações não 
governamentais, etc.) [...]", preservando "os interesses dos estudantes" e garantindo "os critérios de uma educação de qualidade [...]” (UNESCO, 2003, p. 10)

As orientações da Unesco (2003) para a educação secundarista partem de justificativas que visam o desenvolvimento dos indivíduos em uma conjuntura sob o domínio do capital. Com isso, há a defesa de uma educação que desenvolva habilidades gerais e específicas, como a capacidade de liderar, de comunicar-se, de trabalhar em grupo etc., consideradas pela agência como essenciais para acompanhar às mudanças da sociedade.

No documento Políticas Públicas de/para/com juventudes, a Unesco (2004, p. 19) defende uma agenda pública de políticas que contemple os jovens como "atores estratégicos do desenvolvimento". Tomando como referência essa perspectiva, a agência pretende a "[...] formação de recursos humanos aptos para processar as mudanças que se deseja promover na busca do crescimento econômico e da equidade social, da afirmação democrática, do respeito à diversidade, da eliminação de injustiças e desigualdades sociais [...]" (UNESCO, 2004, p. 132).

A Unesco (2004) respalda-se em um "enfoque integrado e transversal", formado por um sistema de alianças nas quais diferentes instituições, organizações sociais, docentes, dirigentes comunitários, empresários, entre outros, poderiam "somar os esforços". De acordo com essa compreensão, a educação é considerada como um "fator chave" (UNESCO, 2004, p. 142) para a formação de "recursos humanos", para o "[...] processo de crescimento econômico sustentável e para o bem-estar social [...]”. (UNESCO, 2004, p. 143)

Ao definir as prioridades para a educação, a Unesco (2004, p. 143-144) elenca como desafios: a universalização do Ensino Fundamental e do Ensino Médio, o estabelecimento de padrões de qualidade e rendimento escolar, a ampliação da equidade entre os diferentes grupos sociais, a democratização da Educação Infantil para crianças de 4 e 5 anos, investimentos "[...] na formação continuada de professores, tendo em vista que seu nível salarial corresponda a patamares dignos [...]" (UNESCO, 2004, p. 144) e na infraestrutura das escolas, entre outras.

Em Reforma da Educação Secundária: rumo à convergência entre a aquisição de conbecimento e o desenvolvimento de habilidade, a agência sugere que os países membros realizem reformas na educação secundarista sintonizadas com a formação de "[...] um repertório de habilidades para a vida, que inclui, entre outras, habilidades analíticas e de resolução de problemas, criatividade, flexibilidade, mobilidade e empreendedorismo" (UNESCO, 2008, p. 11).

Tomando como referência o desenvolvimento de tais habilidades, a Unesco (2008) propõe uma organização curricular para o Ensino Médio, dividida em dois ciclos: um de base geral fundamentado em conhecimentos comuns e outro específico destinado à formação técnica e profissional. O primeiro ciclo é considerado um "requisito mínimo" para a formação de habilidades e competências, no qual seriam adquiridos conhecimentos para o "desenvolvimento individual e social" (UNESCO, 2008, p. 11):

\footnotetext{
Nesse nível de ensino, particularmente durante seu primeiro ciclo, valores e atitudes formados na escola primária são enraizados mais firmemente, acompanhados da aquisição de conhecimentos e habilidades. O primeiro ciclo da educação secundária, portanto, encontra-se conceitualmente dentro do conceito de "educação básica", que é amplamente reconhecido como requisito educacional mínimo para o desenvolvimento individual e social. Daí, que em muitos lugares do mundo, a educação básica seja compulsória e financiada pelo Estado. (UNESCO, 2008, p. 11)
}

Nesse ciclo, haveria uma homogeneização de conteúdos e conhecimentos que "[...] deveriam ser utilizados para consolidar o letramento e a numeralização, as habilidades para a vida e a capacidade de aprender a aprender [...]" (UNESCO, 2008, p. 17). Já no segundo ciclo, haveria

Práxis Educativa, Ponta Grossa, v. 17, e2219945, p. 1-19, 2022 Disponível em: <https://revistas2.uepg.br/index.php/praxiseducativa> 
a articulação entre o currículo básico ou comum e o ensino profissionalizante conforme as experiências desenvolvidas em alguns países europeus:

No segundo ciclo da educação secundária, os países europeus têm experimentado
diversas abordagens de articulação entre educação básica geral, educação técnico-
profissional e treinamento, que incluem diversificação do currículo, aumento do status e
da qualificação docente, melhorias no encaminhamento profissional e intermediação com
o ensino superior. (UNESCO, 2008, p. 18)

A proposta curricular para o segundo ciclo considera a realização de estágios de treinamento profissional, que facilitariam as "[...] condições de escolha, de orientação profissional e de ingresso no mundo do trabalho [...] para todos os alunos do nível secundário" (UNESCO, 2008, p. 24). Nesse ciclo, haveria o diálogo com o mundo do trabalho e com os futuros empregadores, ampliando o leque de opções de carreira e o desenvolvimento de uma vocação (UNESCO, 2008)

Para que essas orientações ganhem materialidade, a Unesco (2008) considera a realização de parcerias entre as instituições públicas e privadas, como as Organizações não Governamentais (ONGs), agências internacionais, empresas etc. No que se refere aos professores que atuariam no segundo nível, a Unesco (2008, p. 30) afirma que: "Todos os docentes da educação técnicoprofissional e treinamento, especialmente os instrutores/capacitadores que ensinam habilidades práticas, deveriam ser considerados parte integrante da profissão docente e reconhecidos como detentores do mesmo estatuto que seus colegas da educação secundária geral”.

Esse modo de conceber a educação está presente em maior ou menor escala no Ensino Médio e Educação Profissional: desafios da integração, de 2010. Nesse documento, as organizadoras Marilza Ragattieri ${ }^{3}$ e Jane Margareth Castro ${ }^{4}$ sistematizam um conjunto de debates sobre a possibilidade de integrar a Educação Profissional ao Ensino Médio, de modo a desenvolver competências gerais (de base científica, para a compreensão do homem, do mundo e da vida em sociedade) e específicas (de caráter técnico, instrumental, para a realização de atividades laborais) (RAGATTIERI; CASTRO, 2010).

Em Ensino Médio e Educação Profissional: desafios da integração, a integração alinha-se às necessidades do capitalismo, e o desenvolvimento de habilidades específicas é elevado como condição para a qualidade da educação e para a garantia de um emprego com melhor remuneração (RAGATTIERI; CASTRO, 2010). Essas habilidades são sistematizadas nos Protótipos curriculares para o Ensino Médio e Ensino Médio integrado: resumo executivo de 2011.

Nesse documento, a Unesco (2011, p. 6) sugere dois "protótipos curriculares" para o Ensino Médio: um é "[...] orientado para o mundo do trabalho e a prática social”, visa à garantia "[...] de aprendizagens necessárias ao desenvolvimento de conhecimentos, atitudes, valores e capacidades básicas para o exercício de todo e qualquer tipo de trabalho" e oportuniza a continuidade dos estudos; e o outro tem como finalidade a "profissionalização mais imediata" e a garantia do desenvolvimento de "[...] habilitações técnicas específicas, atendendo ao objetivo de formação de técnicos de nível médio”.

\footnotetext{
3 Marilza Ragattieri ocupou o cargo de oficial de projetos em educação na Unesco Brasil durante 15 anos, concentrando-se nas áreas do Ensino Médio e da Educação Profissional, tendo atuado junto ao Ministério da Educação (MEC) como consultora em projetos de reformas da educação técnica profissional (UNESCO, 2018).

${ }^{4}$ Jane Margareth de Castro ocupou na Unesco o cargo de assistente sênior em Educação, tendo também atuado no MEC “[...] na reforma do ensino médio, com assessoria aos estados na construção e na execução da política de ensino médio" (UNESCO, 2018, p. 141).
}

Práxis Educativa, Ponta Grossa, v. 17, e2219945, p. 1-19, 2022 Disponível em: < https:// revistas2.uepg.br/index.php/praxiseducativa> 
O primeiro protótipo curricular da Unesco (2011, p. 9) considera que o currículo “[...] dividido em disciplinas estanques, é adequada à perspectiva de transmissão verbal de conhecimentos [...] desconexos e descontextualizados" e, com base nisso, a agência propõe a divisão do currículo em uma parte organizada em conhecimentos comuns e outra em áreas do conhecimento: “(I) Linguagens, códigos e suas tecnologias; (II) Matemática e suas tecnologias; (III) Ciências da Natureza e suas tecnologias; (IV) Ciências Humanas e suas tecnologias" (UNESCO, 2011, p. 11).

No segundo protótipo curricular, a Unesco (2011, p. 17) traz orientações para a integração entre Ensino Médio e o Ensino Técnico Profissional. As orientações para esse protótipo seguem o modelo definido para o primeiro; desse modo, são estruturadas na divisão curricular tomando por base um núcleo articulador e áreas do conhecimento. Para o núcleo comum, a Unesco (2011, p. 17) considera a "[...] preparação para o trabalho e demais práticas sociais" e propõe "objetivos de aprendizagem destinados à educação profissional de nível técnico aos de preparação básica para o trabalho". Nessa proposta, o núcleo comum se diferencia do primeiro protótipo por perder a qualificação "básica" e incluir a "específica".

No Currículo integrado para o Ensino Médio: das normas à prática transformadora, organizado por Ragattieri e Castro (2013), também há a defesa de uma composição disciplinar organizada em áreas do conhecimento (Linguagens, Matemática, Ciências Naturais e Ciências Humanas), nas quais os objetivos são comuns e "[...] relacionados à preparação básica para o trabalho e demais práticas sociais ou à educação profissional” (RAGATTIERI; CASTRO, 2013, p. 64).

No modelo proposto, o desenvolvimento de competências é considerado essencial para a inserção no mercado de trabalho. Para tanto, Currículo integrado para o Ensino Médio: das normas à prática transformadora (RAGATTIERI; CASTRO, 2013, p. 82) recorre ao relatório SCANS ${ }^{5}$ de 1991, o qual defende que "trabalhadores eficazes" são aqueles que: administram recursos, trabalham em equipe, se comunicam, resolvem problemas, operam com sistemas e aparelhos tecnológicos, processam dados e demais informações.

No que se refere às habilidades a serem desenvolvidas na escola, o relatório SCANS confere ênfase às:

Habilidades básicas - leitura, escrita, aritmética e matemática, falar e ouvir;

Habilidades de pensamento - pensar criativamente, tomar decisões, resolver problemas, ver as coisas com os olhos da mente, aprender a aprender, raciocínio;

Qualidades pessoais - responsabilidade individual, autoestima, sociabilidade, autogestão e integridade. (RAGATTIERI; CASTRO, 2013, p. 83).

Esse esquema de competências e habilidades é considerado como "[...] fundamental para qualquer reforma do ensino que se proponha a resolver as demandas diagnosticadas" (RAGATTIERI; CASTRO, 2013, p. 83) na sociedade, e, por isso, são orientadas para a manutenção da atual organização societária do capitalismo.

O conjunto dos documentos da Unesco respalda-se em torno das seguintes orientações para o Ensino Médio: fragmentação curricular em um núcleo comum e áreas do conhecimento; atuação de "instrutores" e "capacitores" no Ensino Médio; universalização do Ensino Médio; desenvolvimento de habilidades gerais e específicas; formação técnica; realização de parcerias com

\footnotetext{
${ }^{5}$ O Relatório SCANS foi um documento encomendado pelo governo norte-americano em 1991, com o objetivo de sistematizar as demandas das empresas para o trabalho no século XXI. Com base nisso, o documento elenca as habilidades e as competências “[...] necessárias para o desempenho adequado no trabalho" a serem desenvolvidas nas escolas dos Estados Unidos (RAGATTIERI; CASTRO, 2013, p. 82).
}

Práxis Educativa, Ponta Grossa, v. 17, e2219945, p. 1-19, 2022 Disponível em: < https:// revistas2.uepg.br/index.php/praxiseducativa $>$ 
a iniciativa privada; protagonismo juvenil e investimentos na infraestrutura das escolas. Dessas orientações, apenas a última converge com as demandas do movimento estudantil para o Ensino Médio.

Nas exposições que dão sequência a este artigo, avaliamos em que medida as orientações da Unesco e as demandas do movimento estudantil se apresentam na reforma do Ensino Médio, Lei $\mathrm{N}^{\circ} 13.415 / 2017$.

\section{A materialização da relação de forças entre o Movimento Estudantil e a Unesco na Lei $\mathbf{N}^{\circ}$ $13.415 / 2017$}

As demandas do movimento estudantil secundarista, para o Ensino Médio, situam-se em torno de uma educação efetivamente pública, que possibilite aos jovens da classe trabalhadora o ingresso aos bancos das universidades e em postos de trabalho com remuneração digna. Para que isso ocorra, os secundaristas consideram a necessidade de uma formação consubstanciada no livre acesso aos conteúdos e aos conhecimentos, com investimentos na educação, valorização docente e fomento às políticas que oportunizem a continuação dos estudos, ou, para aqueles que desejarem, a inserção no mercado do trabalho.

A educação requerida pelo movimento estudantil secundarista aproxima-se de uma escola de "formação humanista" e "cultura geral", que possibilita o contato com o conhecimento sistematizado, insere os jovens na atividade científica e técnica, havendo o equilíbrio entre formação humana e formação para o trabalho. É importante destacarmos que este trabalho não diz respeito ao desenvolvimento das aptidões técnicas para o capitalismo, mas para o desenvolvimento das capacidades intelectuais, possibilitando a criação, a práxis social e a consciência crítica (GRAMSCI, 2001)

As orientações da Unesco para a universalização do acesso à educação secundarista, a conhecimentos gerais e específicos e para a realização de investimentos no Ensino Médio revestemse de caráter interessado na manutenção da hegemonia. Isso ocorre em razão de que a Unesco toma por base as demandas do mercado para justificar a necessidade de universalizar um conjunto de habilidades e de competências (gerais e específicas) que permitam aos jovens adentrarem nesse mercado, formando o que denomina de "personalidades produtivas" (UNESCO, 2008, p. 11).

A análise dos dados de pesquisa evidencia a existência de dois projetos distintos de Ensino Médio, nos quais as "forças políticas" expressam concepções de mundo que se alinham a interesses específicos. A partir das análises, é possível afirmarmos que as demandas do movimento estudantil objetivam uma educação que se aproxima de uma perspectiva "ético política", pois possibilita o desenvolvimento humano e a transformação social. Já as orientações da Unesco atendem aos interesses da classe dominante, do mercado e dos segmentos privados.

Na relação de forças entre movimento estudantil e Unesco, o Estado acolheu as orientações da agência para a Lei $\mathrm{N}^{\circ} 13.415 / 2017$, veiculando os interesses políticos e econômicos para a manutenção da hegemonia. Schlesener (2016, p. 34) aponta que “[...] a verdadeira função do Estado moderno [...]" é "[...] garantir o desenvolvimento econômico e os interesses da classe que está no poder; a valorização da livre iniciativa na esfera privada [...]”, de modo a implementar "[...] mecanismos sempre mais sofisticados de exploração da força de trabalho".

É nesse sentido que a Lei No 13.415/2017 espelha a síntese do jogo de "forças políticas" presentes na sociedade civil, nas quais o nível de autoconsciência e a organização alcançados pelas classes dominantes expressam que o "econômico corporativo" (GRAMSCI, 2016, p. 41) é força

Práxis Educativa, Ponta Grossa, v. 17, e2219945, p. 1-19, 2022 Disponível em: <https:// revistas2.uepg.br/index.php/praxiseducativa $>$ 
imperante no novo Ensino Médio. Os interesses e as demandas do movimento estudantil foram desconsiderados em face de interesses que contribuem para a manutenção dos mecanismos de dominação da sociedade de classes.

No Quadro 1, a seguir, sistematizamos as demandas do movimento estudantil e as orientações da Unesco para o Ensino Médio, em busca de explicitarmos como a relação de forças entre ambos se expressou na Lei $\mathrm{N}^{\circ} 13.415 / 2017$.

Quadro 1 - Demandas do movimento estudantil, orientações da Unesco e a materialização na Lei No 13.415/2017

\begin{tabular}{|c|c|c|}
\hline $\begin{array}{l}\text { Demandas do } \\
\text { movimento estudantil } \\
\text { para o Ensino Médio }\end{array}$ & $\begin{array}{c}\text { Orientações da Unesco para o Ensino } \\
\text { Médio }\end{array}$ & $\begin{array}{c}\text { Materialização na Lei No } \\
\text { 13.415/2017 }\end{array}$ \\
\hline $\begin{array}{l}\text { Acesso a saberes } \\
\text { científicos, filosóficos, } \\
\text { artísticos, sociológicos e } \\
\text { culturais. }\end{array}$ & $\begin{array}{l}\text { Fragmentação curricular em um "Núcleo de } \\
\text { preparação básica para o trabalho e demais } \\
\text { práticas sociais" (UNESCO, 2011, p. 10-11) } \\
\text { e quatro áreas do conhecimento: (I) } \\
\text { Linguagens, códigos e suas tecnologias; (II) } \\
\text { Matemática e suas tecnologias; (III) Ciências } \\
\text { da Natureza e suas tecnologias; (IV) } \\
\text { Ciências Humanas e suas tecnologias" } \\
\text { (UNESCO, 2011, p. 11). }\end{array}$ & $\begin{array}{l}\text { Fragmentação curricular: núcleo } \\
\text { comum e Itinerários formativos } \\
\text { estruturados em áreas do } \\
\text { conhecimento: I - linguagens e } \\
\text { suas tecnologias; II } \\
\text { - matemática e suas tecnologias; } \\
\text { III - ciências da natureza e suas } \\
\text { tecnologias; IV - ciências } \\
\text { humanas e sociais aplicadas; V } \\
\text { - formação técnica } \\
\text { profissional (BRASIL, 2017). }\end{array}$ \\
\hline $\begin{array}{l}>\text { Formação e qualificação } \\
\text { docente. }\end{array}$ & $\begin{array}{l}\text { “Instrutores/capacitadores" devem ser “[...] } \\
\text { considerados parte integrante da profissão } \\
\text { docente" (UNESCO, 2008, p. 30). }\end{array}$ & $\begin{array}{l}\text { Profissionais com "notório } \\
\text { saber" poderão "[...] ministrar } \\
\text { conteúdos de áreas afins à sua } \\
\text { formação ou experiência } \\
\text { profissional” (BRASIL, 2017, p. } \\
\text { 2). }\end{array}$ \\
\hline$>$ Formação humana. & $\begin{array}{l}\text { A formação de nível médio “[...] assegurará } \\
\text { aos indivíduos a flexibilidade necessária para } \\
\text { responder às exigências do mercado de } \\
\text { trabalho por meio da aquisição de novas } \\
\text { habilidades profissionais [...]”. (UNESCO, } \\
\text { 2008, p. 24-25). }\end{array}$ & $\begin{array}{l}>\text { Formação para o mercado de } \\
\text { trabalho. } \\
>\text { Formação técnica. }\end{array}$ \\
\hline $\begin{array}{l}\text { Investimento na } \\
\text { educação e na escola } \\
\text { pública. }\end{array}$ & $\begin{array}{l}\text { "O acesso de massa ao ensino médio } \\
\text { envolverá, necessariamente, um esquema de } \\
\text { parceria entre os governos e outros } \\
\text { provedores (privados, organizações não } \\
\text { governamentais, etc.) [...]" (UNESCO, } \\
\text { 2003, p. 10) } \\
\text { "O espaço a infra-estrutura, as instalações e } \\
\text { os recursos que a escola aos alunos, } \\
\text { professores e demais integrantes da } \\
\text { comunidade escolar, são suportes } \\
\text { importantes no processo de ensino- } \\
\text { aprendizagem" (UNESCO, 2004, p. 215). }\end{array}$ & $\begin{array}{l}\text { Realização de parcerias público- } \\
\text { privadas. } \\
\text { Recursos transferidos } \\
\text { anualmente de acordo com a } \\
\text { disponibilidade orçamentária a } \\
\text { ser definida. }\end{array}$ \\
\hline $\begin{array}{l}\text { Ensino } \\
\text { democrático. }\end{array}$ & $\begin{array}{l}\text { O Ensino Médio pode contribuir para } \\
\text { "Formular projetos de vida, detectar } \\
\text { oportunidades de trabalho e adequar a } \\
\text { escolha profissional às preferências e } \\
\text { possibilidades pessoais" (RAGATTIERI; } \\
\text { CASTRO, 2013, p. 221). }\end{array}$ & $\begin{array}{l}\text { Ênfase nos projetos de vida dos } \\
\text { estudantes. }\end{array}$ \\
\hline
\end{tabular}

Fonte: As autoras. Dados da pesquisa.

A leitura do Quadro 1 evidencia que o novo Ensino Médio carrega, em seu bojo, um conjunto de elementos em torno do projeto de educação da Unesco. Percebemos que, na relação de forças em torno de dois projetos de Ensino Médio, embora tenha havido resistência dos

Práxis Educativa, Ponta Grossa, v. 17, e2219945, p. 1-19, 2022 Disponível em: <https:// revistas2.uepg.br/index.php/praxiseducativa $>$ 
estudantes, por meio do movimento de ocupações escolares em todo o país, preponderou aquele que corresponde às exigências do mercado e do mundo da produção.

Orientações da Unesco para o Ensino Médio, como a fragmentação curricular em um núcleo comum e áreas do conhecimento, a atuação de profissionais não vinculados à carreira docente, a formação para o mercado com o desenvolvimento de habilidades gerais e específicas, a ênfase no Ensino Técnico Profissional, a realização de parcerias público-privadas e o protagonismo juvenil são elementos que se fazem presentes na atual reforma do Ensino Médio.

A reforma do Ensino Médio, então, sintetiza os conteúdos políticos que mantêm viva a relação de domínio da classe dominante em toda a sociedade civil. A validação desse domínio pelo Estado não se deu apenas pelo acato à maioria das orientações da agência internacional, mas também porque ele apoiou algumas das orientações indicadas em Protótipos curriculares para o Ensino Médio (UNESCO, 2011), documento que compõe uma série de elementos que influenciaram diretamente na configuração do novo Ensino Médio, e, como a própria agência reconhece, foi apoiado pelo MEC.

O conjunto dos documentos da Unesco analisados expressam que a educação do consenso foi idealizada e capilarizada na sociedade civil; em outras palavras, que os pressupostos da agência se centram em objetivos que visam o desenvolvimento de habilidades e competências requeridas pelo capital e que as desigualdades sociais são passíveis de serem solucionadas via educação. Em oposição a esse modo de conceber a educação, o movimento estudantil demanda uma formação que possibilite à juventude da classe trabalhadora desenvolver o pensamento crítico, organizar-se politicamente e inserir-se no mundo do trabalho. Convém destacarmos que não se trata de qualquer trabalho, pois os jovens criticaram uma educação essencialmente técnica, voltada para a produção, e defenderam uma formação para a criação, a interação com o objeto e o desenvolvimento das potencialidades humanas.

\section{Considerações finais}

A reforma do Ensino Médio situa-se no bojo das reformas educacionais que atendem aos interesses do capital, na medida em que prevê a fragmentação curricular em um núcleo comum e em itinerários formativos, ofertados de acordo com a disponibilidade dos sistemas de ensino, a formação articulada com os imperativos do capital, a possibilidade de estabelecer parcerias entre segmentos públicos e privados e a atuação de profissionais de "notório saber". Esses elementos alinham-se a uma proposta educacional coadunada com a hegemonia da sociedade de classes. A demanda do sistema capitalista para a educação ancora-se em torno da profissionalização em massa, aligeirada e concentrada nas necessidades do mercado, garantindo ao máximo a exploração da força de trabalho e, consequentemente, a extração de mais valia. Para a efetivação dos interesses capitalistas, a educação molda-se a um modelo formativo que inibe o desenvolvimento do pensamento crítico, produzindo o trabalhador flexível, submisso e conformado com a situação de exploração que vivencia cotidianamente.

Em oposição a isso, as demandas do movimento estudantil são orientadas por perspectivas que visam uma educação pública com livre acesso a conhecimentos históricos, científicos, filosóficos, artísticos, entre outros, possibilitando a ascensão dos jovens ao Ensino Superior e ao mercado de trabalho. De acordo com a Ubes, a aquisição de tais conhecimentos envolve investimentos na área da Educação, formação e qualificação docente e o fomento a políticas educacionais sintonizadas com as necessidades da juventude. Desse modo, poder-se-ia garantir o equilíbrio entre a formação humana e a formação para o mundo do trabalho, aqui entendido como aquele que estabelece aprendizados e experiências para a práxis social.

Práxis Educativa, Ponta Grossa, v. 17, e2219945, p. 1-19, 2022 Disponível em: <https:// revistas2.uepg.br/index.php/praxiseducativa $>$ 
Das orientações presentes nos documentos da Unesco que, notadamente inspiraram a reforma do Ensino Médio - Lei $N^{\circ}$ 13.415/2017, podem ser destacados: a fragmentação do currículo em um núcleo comum e áreas do conhecimento; a possibilidade de atuação de instrutores como docentes; o fomento à formação técnica; e a realização de parcerias com agentes privados. Essas orientações partiram de um "laboratório de ideias" (UNESCO, 2008, p. 32) cujo objetivo é dar visibilidade aos interesses hegemônicos, sendo articuladas à formação cultural de 6.777 .892 de jovens matriculados no Ensino Médio, em escolas públicas do país, conforme o Instituto Nacional de Estudos e Pesquisas Educacionais Anísio Teixeira - Inep (2019).

A influência dessas orientações no novo Ensino Médio, não se deu de forma isolada, pois elas se alinham aos interesses das classes que são hegemônicas na economia, na política e na cultura, portanto ao núcleo burguês com o qual a agência mantém vínculos. Desse modo, a "força política" da sociedade civil se condensou nas articulações realizadas, na autoconsciência e na organização da classe dominante.

O Estado, como entidade político-organizativa controlada por essa classe, deu materialidade a um projeto de Ensino Médio que visa a reprodução da ordem social hegemônica. As estratégias que educam o consenso, que alimentam a ampliação da exploração do trabalho, foram elaboradas e reconfiguradas ao contexto e aos interesses de uma época e, desse modo, a reforma do Ensino Médio - Lei N ${ }^{\circ}$ 13.415/2017 condensa um conteúdo político que ganhou materialidade nas ações de um Estado que não é "ético político", mas que se apresenta cada vez mais à imagem e à semelhança da burguesia.

\section{Referências}

BOUTIN, A. C. B. D. A relação de forças entre a Unesco e o Movimento Estudantil e sua materialização na reforma do Ensino Médio, através da Lei $\mathbf{n}^{\circ} \mathbf{1 3 . 4 1 5 / 2 0 1 7}$. 2020. Tese (Doutorado em Educação) - Universidade Estadual de Ponta Grossa, Ponta Grossa, 2020.

BRASIL. Lei $\mathrm{N}^{\circ}$ 13.415, de 16 de fevereiro de 2017. Altera as Leis $\mathrm{N}^{\text {os }} 9.394$, de 20 de dezembro de 1996, que estabelece as diretrizes e bases da educação nacional, e 11.494, de 20 de junho 2007, que regulamenta o Fundo de Manutenção e Desenvolvimento da Educação Básica e de Valorização dos Profissionais da Educação, a Consolidação das Leis do Trabalho - CLT, aprovada pelo Decreto-Lei no 5.452, de 1o de maio de 1943, e o Decreto-Lei no 236, de 28 de fevereiro de 1967; revoga a Lei no 11.161, de 5 de agosto de 2005; e institui a Política de Fomento à Implementação de Escolas de Ensino Médio em Tempo Integral. Diário Oficial da União: seção 1, Brasília, DF, n. 35, p. 1-3, 17 fev. 2017.

BRASIL. Medida Provisória No 746, de 22 de setembro de 2016. Institui a Política de Fomento à Implementação de Escolas de Ensino Médio em Tempo Integral, altera a Lei no 9.394, de 20 de dezembro de 1996, que estabelece as diretrizes e bases da educação nacional, e a Lei no 11.494 de 20 de junho 2007, que regulamenta o Fundo de Manutenção e Desenvolvimento da Educação Básica e de Valorização dos Profissionais da Educação, e dá outras providências. Diário Oficial da União: edição extra, seção 1, Brasília, DF, n. 184-A, p. 1-2, 23 set. 2016 a.

BRASIL. Proposta de Emenda à Constituição $\mathbf{N}^{\circ}$ 55, de 2016. Altera o Ato das Disposições Constitucionais Transitórias, para instituir o Novo Regime Fiscal, e dá outras providências. Brasília: Senado Federal, [2016b]. Disponível em: https://legis.senado.leg.br/sdleggetter $/$ documento?dm $=3877571 \&$ ts $=1606767233079 \&$ disposition=inline. Acesso em: 12 fev. 2022. 
BRASIL. Ministério da Educação. Unesco. Gov.br, 2018. http://portal.mec.gov.br/encceja2/480-gabinete-do-ministro-1578890832/assessoria-internacional-1377578466/20747-unesco.

Disponível em: 12 fev. 2022.

FERREIRA, E. B. A contrarreforma do ensino médio no contexto da nova ordem e progresso. Educação \& Sociedade, Campinas, v. 38, n. 139, p. 293-308, abr./jun. 2017. DOI: DOI: https://doi.org/10.1590/ES0101-73302017176594

GRAMSCI, A. Cadernos do cárcere, vol. 1: introdução ao estudo da filosofia, a filosofia de Benedetto Croce. Rio de Janeiro: Civilização Brasileira, 2014.

GRAMSCI, A. Cadernos do cárcere, vol. 2: os intelectuais, o princípio educativo, jornalismo. Rio de Janeiro: Civilização Brasileira, 2001.

GRAMSCI, A. Cadernos do cárcere, vol. 3: Maquiavel, notas sobre o Estado e a Política. Rio de Janeiro: Civilização Brasileira, 2016.

INEP. Instituto Nacional de Estudos e Pesquisas Educacionais Anísio Teixeira. Censo Escolar. Brasília: INEP, 2019.

LOPES, V. de F. M.; MOREIRA, E. E. A Reforma do Ensino Médio: mudar para deixar como está. Revista Labor, Fortaleza, v. 1, n. 25, p. 90-104, abr. 2021.

MAINARDES, J.; CURY, C. R. J. Ética na pesquisa: princípios gerais. In: ANPED. Associação Nacional de Pesquisa em Pós-Graduação. Ética e pesquisa em educação: subsídios. Rio de Janeiro: ANPED, 2019. p. 24-29. Disponível em: https://www.anped.org.br/sites/default/files/etica_e_pesquisa_em_educacao_-_isbn_final.pdf. Acesso em: 10 fev. 2022.

RAGATTIERI, M.; CASTRO, J. M. Ensino Médio e Educação Profissional: desafios da integração. Brasília: Unesco, 2010.

RAGATTIERI, M.; CASTRO, J. M. Currículo integrado para o Ensino Médio: das normas à prática transformadora. Brasília: Unesco, 2013.

SCHLESENER, A. H. Grilhões invisíveis: as dimensões da ideologia, as condições de subalternidade e a educação em Gramsci. Ponta Grossa: UEPG, 2016.

SEMERARO, G. Gramsci e a sociedade civil: cultura e educação para a democracia. Petrópolis: Vozes, 1999.

UBES. União Brasileira dos Estudantes Secundaristas. Nota de repúdio à MP do Ensino Médio. Ubes, São Paulo, 22 set. 2016. Disponível em: http://ubes.org.br/2016/ubes-nota-de-repudio-amp-do-ensino-medio/. Acesso em: 31 dez. 2019.

UBES. União Brasileira dos Estudantes Secundaristas. Resolução de Educação aprovada no $42^{\circ}$ Conubes. Ubes, São Paulo, 2017. Disponível em: https://ubes.org.br/ubesnovo/wpcontent/uploads/2017/12/RESOLU $\%$ C3\%87\%C3\%83O-EDUCA\%C3\%87\%C3\%83O.pdf.

Acesso em: 31 dez. 2019.

UBES. União Brasileira dos Estudantes Secundaristas. Construindo nossa escola. São Paulo: Ubes, 2018. 
UBES. União Brasileira dos Estudantes Secundaristas. UBES, 40 milhões de estudantes: lutas e conquistas. Ubes, São Paulo, 2022. Disponível em: https://ubes.org.br/a-ubes/. Acesso em: 11 jan. 2022.

UNESCO. Organizações das Nações Unidas para a Ciência e Cultura. Constituição das Nações Unidas para a Ciência e Cultura. Representação da Unesco no Brasil. Brasília: Unesco, 2002.

UNESCO. Organizações das Nações Unidas para a Ciência e Cultura. Ensino Médio para o século XXI: desafios, tendências e prioridades. Brasília: Unesco, 2003.

UNESCO. Organizações das Nações Unidas para a Ciência e Cultura. Políticas públicas de/para/com as juventudes. Brasília: Unesco, 2004.

UNESCO. Organizações das Nações Unidas para a Ciência e Cultura. Marco estratégico para a UNESCO no Brasil. Brasília: Unesco, 2006.

UNESCO. Organizações das Nações Unidas para a Ciência e Cultura. Reforma da educação secundária: rumo à convergência entre a aquisição de conhecimento e desenvolvimento de habilidades. Brasília: Unesco, 2008.

UNESCO. Organizações das Nações Unidas para a Ciência e Cultura. Protótipos curriculares de Ensino Médio e Ensino Médio integrado: resumo executivo. Brasília: Unesco, 2011.

Recebido em 14/11/2021

Versão corrigida recebida em 09/02/2022

Aceito em 10/02/2022

Publicado online em 17/02/2022 